DOSSIÊ

\title{
Sementes de Marielle no Cerrado Baiano
}

\author{
Paula Vielmo, Instituto Federal da Bahia \\ Indiara de Souza CONCEIÇÃO, Universidade do Estado da Bahia \\ Raycá da Silva MoraIs, Universidade do Estado da Bahia
}

A repercussão da execução da vereadora e militante Marielle Franco foi nacional, internacional e também local. Neste breve relato de experiência, temos como objetivo refletir sobre o legado de Marielle Franco a partir de três atos públicos realizados no município de Barreiras, interior da Bahia, nos anos de 2018 e 2019. Retomamos sua biografia e a divulgação do crime, em seguida relatamos e analisamos os dois atos públicos realizados pelo PSOL - Barreiras na Praça Castro Alves, em 2018 e 2019 e o ato público organizado pelo Movimento Estudantil da Universidade do Estado da Bahia, Campus IX. As informações sobre Marielle Franco, sua trajetória e o crime, partem basicamente de fontes jornalísticas e vídeos disponíveis no YouTube ou no site que leva sua memória política. A partir de locais de fala distintos, avaliamos os reflexos do legado de Marielle para impulsionar a criação artística, a identificação com a negritude, a organização e fortalecimento dos movimentos sociais, de candidaturas de mulheres negras e as dificuldades no cenário político de ascensão da extrema-direita, inclusive em Barreiras.

PALAVRAS-Chave: Marielle Franco. Legado. Atos. Barreiras. 


\section{"Eu sou porque nós somos"}

Marielle Francisco da Silva, conhecida como Marielle Franco, brasileira (bem) vinda ao mundo em 27 de julho de 1979 no Rio de Janeiro, nasceu e cresceu na favela do Complexo da Maré e se apresentava publicamente como "cria da Maré". "Eu sou Marielle Franco, mulher, negra, mãe, da favela" (QUEM..., 2016). Também socióloga e vereadora do Rio de Janeiro pelo Partido Socialismo e Liberdade (PSOL). Uma identidade múltipla de alguém diversa, mas não dispersa, como ela mesma se referia às mulheres e que na campanha para vereadora trazia como três pilares principais os debates de gênero, de raça e cidade, enfatizando sobre as mulheres negras na favela (MARIELLE..., 2018).

Adentrou ao mundo do trabalho, como muitas brasileiras semelhantes a ela, aos 11 anos de idade para contribuir com a renda familiar. Em 1998 ingressou no cursinho pré-vestibular comunitário e a partir dos anos 2000 iniciou a militância no campo dos Direitos Humanos após a morte de uma amiga, vítima de bala perdida. Aos 19 anos, pariu a sua única filha, Luyara Franco e desde 2004 se relacionava com Mônica Benício, sua companheira até a morte (FUKS, 2019; QUEM..., 2016).

Marielle graduou-se em Ciências Sociais pela PUC-Rio e cursou mestrado em Administração Pública pela Universidade Federal Fluminense (UFF). Sua dissertação intitulada "UPP - A redução da favela a três letras: uma análise da política de segurança pública do Estado do Rio de Janeiro" objetivou "demonstrar que as Unidades de Polícia Pacificadora (UPPs), enquanto política de segurança pública adotada no estado do Rio de Janeiro, reforçam o modelo de Estado Penal, absolutamente integrado ao projeto neoliberal” (FRANCO, 2014, p. 13).

É muito importante falar da intelectualidade de Marielle Franco, porque nas palavras de bell hooks (1995) as mulheres negras são desestimuladas a serem intelectuais e "o trabalho intelectual é uma parte necessária da luta pela libertação, fundamental para os esforços de todas as pessoas oprimidas e/ou exploradas que passariam de objeto a sujeito, que descolonizariam e libertariam suas mentes" (hooks, 1995, p. 466) e sem qualquer dúvida, para nós, Marielle é uma importante referência também intelectual.

Segundo o site Florescer por Marielle (2019), ela coordenou por anos a Comissão de Direitos Humanos e Cidadania da Assembleia 
Legislativa do Rio de Janeiro, quando trabalhou junto ao mandato de Marcelo Freixo. Em 2016, foi eleita vereadora do Rio de Janeiro para o mandato 2017-2020 com 46.052 votos, a quinta maior votação. Sabemos que suas principais bandeiras de luta giravam em torno dos Direitos Humanos, relações de gênero, feminismo e combate à violência contra as mulheres, população negra e LGBTQ+.

Durante o período de vereança, presidiu a Comissão da Mulher da Câmara e propôs treze Projetos de Leis, os quais destacamos: PL 0265/2017, sobre as lei das casas de parto; PL 0017/2017, espaço coruja / espaço infantil noturno (aprovado postumamente); PL 0016/2017 pra fazer valer o aborto legal no Rio; PL 0072/2017 que inclui o dia da luta contra a homofobia, lesbofobia, bifobia e transfobia no calendário oficial da cidade; PL 0103/2017, que inclui o dia de Tereza de Benguela e da mulher negra no calendário oficial da cidade do Rio de Janeiro (aprovado postumamente); PL 0288/2017 que inclui o dia municipal de luta contra o encarceramento da juventude negra no calendário oficial da cidade e o PL 0082/2017 que inclui o dia da visibilidade lésbica no calendário oficial da cidade do Rio de Janeiro (reprovado por dois votos). Também na condição de parlamentar, criticou enfaticamente a intervenção federal no Rio de Janeiro e a atuação da Polícia Militar, tendo denunciado inúmeros casos de abuso de autoridade por parte de policiais contra moradores da periferia carioca (FRANCO, 2019).

Esta biografia finda aos 38 anos, no dia 14 de março de 2018, quando treze balas 9 milímetros do lote UZZ-18 da Companhia Brasileira de Cartuchos (CBC) foram usadas para executar a vereadora Marielle Franco, vitimando também seu motorista, Anderson Gomes. Marielle havia recém saído de uma atividade com mulheres na Casa das Pretas, um espaço coletivo de mulheres negras na Lapa, centro do Rio. Ela viveu e morreu em luta por aquilo que acreditava, a movia e também nos toca.

Era noite quando a notícia do assassinato político rapidamente tomou os telejornais do país. Em Salvador, Bahia, Brasil, acontecia a $13^{\text {a }}$ edição do Fórum Social Mundial (FSM 2018), importante espaço promovido por organizações e movimentos sociais em contraposição ao neoliberalismo. A comoção foi generalizada e no dia seguinte, 15 de março, as atividades do Fórum foram paralisadas, dando lugar a uma marcha de luto e de luta em prol da memória de Marielle Franco e exigindo a apuração da execução. Muitas companheiras de Marielle que 
estavam por lá relataram emocionadas sobre a importância de sua existência.

O fato gerou repercussão internacional, noticiada na imprensa europeia em jornais espanhois como El País e El Mundo, o inglês The Guardian, o francês Le Figaro, o italiano RaiNews e o jornal português Público. Em Portugal, segundo divulgado pelo portal Agência Brasil (2018), foram organizados diversos eventos em homenagem à Marielle Franco, com cobrança específica do Deputado Francisco Assis, do Partido Socialista, sobre a urgência das investigações do assassinato político (CAZARRÉ, 2018). Pela América Latina, a morte foi noticiada pela Rede de Televisão Venezuelana teleSUR e pelos jornais argentinos Notas Periodismo Popular, Marcha Noticias e Resumen Latinoamericano, pelo colombiano Informa, pelo uruguaio La Diaria e pelo chileno La Nación. Os eixos em destaque na cobertura dos meios estrangeiros foram o papel ativo da militante na luta pelos direitos humanos de negras e negros e a denúncia da violência contra as comunidades pobres da capital fluminense (MÍDIA, 2018).

Marielle Franco, apesar da atuação extremamente relevante e reconhecida tanto pela votação expressiva quanto pela repercussão após a sua execução, ficou mais conhecida postumamente. Nós, que escrevemos coletivamente este registro reflexivo, não a conhecíamos antes dessa fatalidade, mas nos sentimos tocadas e tocado pelo seu bravo exemplo de luta, pela coerência, por identificação com as causas de luta e por fim, pelo seu legado de resistência e de semeadura. A partir do conhecimento de sua história e defesa da vida e dos direitos dos grupos minorizados, sentimos atravessados por um sentimento que traduz um pouco do caminho feito por ela, que seria a resiliência, esse poder de se reconstruir, brotar com muito mais força e adaptar-se às mudanças.

Assim, considerando a ampla repercussão transnacional do assassinato de Marielle e da sua trajetória inspiradora, resolvemos por pensar o nosso local: Barreiras, no oeste da Bahia, localizada na maior fronteira agrícola do Nordeste e um pólo agropecuário, político e universitário da região, com forte imigração de povos de diversas regiões do Brasil, principalmente sulistas e desorganização dos Movimentos Sociais. Barreiras localiza-se a $872 \mathrm{~km}$ da capital baiana, Salvador e a 615 km da capital do país, Brasília.

Com população estimada pelo IBGE (2019) de 155. 439 pessoas, é uma cidade marcada por desigualdade social, racial e sexual, logo, 
atravessada por todas as pautas pelas quais Marielle lutava. A partir desse contexto, objetivamos refletir sobre o legado de Marielle Franco a partir de três atos públicos realizados no município de Barreiras, interior da Bahia, nos anos de 2018 e 2019, considerando como sementes de Marielle no cerrado baiano. Antes, porém, consideramos relevante localizar nossa diversidade sociológica para essa escrita de três pessoas: uma mulher negra, de 24 anos, estudante do curso de Letras na Universidade do Estado da Bahia; uma mulher branca, de 35 anos, servidora pública pós-graduada, militante feminista e dirigente do PSOL; um homem negro, de 27 anos, estudante do curso de Letras na Universidade do Estado da Bahia, residentes em Barreiras, local de onde partimos para escrever este breve texto.

Trata-se de um relato de experiência de três atividades e participações militantes, das quais fomos parte ativa, mesmo que não as três pessoas nos três momentos. Nossas informações sobre Marielle Franco, sua trajetória e o crime, possuem como fontes matérias jornalísticas e vídeos da vereadora, disponíveis no YouTube ou, ainda, no site que leva sua memória política.

\section{Ato 1: 20/03/2018, Praça Castro Alves}

Diante das dificuldades já mencionadas, o PSOL da cidade (Barreiras, BA), organizou um ato público no dia 20 de março, às $12 \mathrm{~h}$ na Praça Castro Alves, a mais movimentada por trabalhadoras/es e estudantes que dependem do transporte coletivo, para que assim a atividade em busca de justiça tivesse um maior alcance populacional. A fim de contribuir com a conscientização social foram produzidos cartazes exigindo respostas, um varal com fotos e frases de Marielle e distribuídos panfletos para provocar a reflexão e diálogo.

Como o crime já estava sendo noticiado pela imprensa nacional e internacional, boa parte das pessoas no local tinham noção do que se tratava, aglutinando cerca de trinta pessoas. Algumas se aproximaram para participar do ato, outras comentavam entre si a decepção pelo ocorrido e as consequências por vir. Havia um clima misturando medo, indignação e resistência, perceptível pelas falas das pessoas presentes.

Observamos que apesar da "desinformação" que assola a população brasileira, incluindo a barreirense, havia um pouco de consciência sobre os acontecimentos e o sentimento de que a passividade 
não é a melhor escolha. Populares que estavam ao redor apenas ouvindo enquanto esperavam o transporte não demonstravam interesse suficiente, aparentando descrença com a conjuntura política, mesmo que se tratasse de uma vida interrompida por interesses políticos, já que para nós, naquele momento era explícito que se tratava de uma execução política.

Haviam outras pessoas desorientadas aplaudindo a ascensão da direita no nosso país sem compreender que as mesmas são o alvo das políticas neoliberais. Em contrapartida o ato reuniu estudantes do Ensino Médio, das Universidades públicas da cidade, professoras e muitas mulheres, além da militância do Partido, todas e todos buscando estratégias para uma mudança social.

Avaliamos como um importante ato a partir da organização das falas. Inicialmente foi comentado o porquê de estarmos unidas/os ocupando aquele espaço, em seguida foi apresentada a trajetória da vereadora Marielle Franco e o que significava a execução como tentativa de silenciamento dos grupos socialmente minorizados que através dessa mulher negra estavam ocupando um outro lugar em nosso país.

O microfone, aberto, ecoou reflexões sobre violência contra as mulheres, sobre como a execução havia mobilizado para a luta e as situações de ataques à biodiversidade do cerrado, chamando para apoiar a luta em defesa das águas e palavras que buscavam provocar a empatia nas pessoas presentes. Ao final, uma faixa de TNT preta com letras amarelas foi afixada e deixada na Praça, onde lia-se: LUTE COMO MARIELLE!

\section{Ato 2: 14/03/2019, Praça Castro Alves}

Dois dias antes de completar um ano da execução sem identificação de quem havia matado Marielle, foram identificados os assassinos, mas permanece até hoje: “quem mandou matar Marielle?". Todavia, no dia 14 de março de 2019, foi realizado o segundo ato na cidade de Barreiras (BA) organizado pelo mesmo Partido (PSOL), no mesmo local e horário: ao meio dia na Praça Castro Alves.

A atividade foi pensada para dar continuidade ao pedido de justiça pela execução de Marielle que completava um ano sem respostas e também pós eleição de Jair Bolsonaro (PSL) como presidente. Diferente do primeiro ato essa atividade contou com a presença de 
menos pessoas, olhares e comentários maldosos direcionados a quem estava ali lutando contra o silenciamento, ficando explícito os diversos ataques que a esquerda vem sofrendo no Brasil.

Novamente as pessoas que estavam dispersas foram chamadas para refletir e questionar suas ações em busca de mudança no meio em que estamos inseridos. Como o ato contou com menos pessoas decidimos dialogar um pouco mais com as que estavam um pouco distantes, mas recebiam os panfletos. Além de destacar as pautas do ato tentamos analisar a reação das pessoas diante de tantos absurdos. Durante as falas foram trazidos pontos importantes como fatos semelhantes entre a realidade local onde vivia Marielle e a realidade dos moradores da cidade de Barreiras, enfatizando sobre a condição da mulher negra na sociedade. Após as falas teve apresentações de poesias como uma maneira de reafirmar a intelectualidade e cultura negra existente em nosso país. Reproduzimos abaixo uma poesia autoral recitada por Diego Cruz, geógrafo militante e dirigente do PSOL Barreiras:

Marielle foi luta, Jean será, pelos companheiros que tombam na batalha, muita resiliência.

Vivemos tempos sombrios, momentos de reflexão, Está faltando ao ser humano afeto e compaixão

O girassol vai brilhar em nosso coração Trazendo o PSOL pra essa multidão.

Diego Cruz

\section{Ato 3: 14/03/2019, Universidade do Estado da Bahia / Campus IX}

“Quem mandou matar Marielle Franco?”. Está pergunta motivou estudantes da UNEB - Universidade do Estado da Bahia, em Barreiras, a realizar o ato que lembrou 1 ano da execução da vereadora Marielle Franco, que se destacou como militante atuante, por defender os direitos das vidas das mulheres negras; das famílias que moram em periferias; comunidade LGBTQ+; e por denunciar as milícias. 
A proposta dos estudantes foi de levar para o campo acadêmico as discussões sobre os processos de existência dos grupos minorizados e cobrar por justiça; resgatar o legado e reafirmar as lutas das quais ela militava. Tendo em vista de que o público presente no ato, viu-se representado nas narrativas de luta defendidas pela vereadora e que dentro da academia existe uma diversidade de público que sofre uma série de injustiça social e política.

Durante $o$ ato ocorreu falas muito importantes acerca da trajetória de vida de Marielle, relatos pessoais de estudantes e professoras; apresentações artísticas através de músicas e recitação de poemas.

A atividade dentro da universidade que até então não havia discutido os temas de gênero, raça e cidade, possibilitou o debate a partir da realidade semelhante da trajetória, orientação sexual, condição social e classe social, que existe entre Marielle e a comunidade acadêmica. Principalmente das universidades públicas.

\section{"Eles tentaram nos enterrar, mas não sabiam que éramos sementes!"}

A repercussão política eleitoral da execução de Marielle Franco, mulher negra favelada que ousou ocupar um espaço político hegemonizado por homens brancos heterossexuais impulsionou em outubro de 2018 a candidatura de inúmeras mulheres negras. "O Rio de Janeiro elegeu quatro mulheres negras amigas de Marielle, todas pelo PSOL: Talíria Petrone, deputada federal, e Renata Souza, Mônica Francisco e Dani Monteiro, que trabalhavam como assessoras da vereadora, deputadas estaduais" (ANTUNES, 2018).

Ainda segundo matéria de Leda Antunes (2018), outras mulheres negras, foram eleitas pelo país: a vereadora de Belo Horizonte Áurea Carolina (PSOL) foi eleita deputada federal; a advogada popular Andréia de Jesus (PSOL) eleita deputada estadual em Minas Gerais; a chapa coletiva Juntas (PSOL) em Pernambuco elegeu cinco mulheres, dentre elas Robeyoncé Lima, mulher negra, transexual, advogada; em São Paulo foram eleitas deputadas estaduais a educadora, ativista e mulher trans Érica Malunguinho da Silva (PSOL) e a ativista e estudante de gerontologia, Erika Hilton, mulher trans e negra que faz parte da Bancada Ativista, chapa coletiva do PSOL, que conta também com a 
jornalista e ativista ambiental, mulher negra, Mônica Seixas. Na Bahia foi eleita a primeira deputada estadual negra: a professora Olívia Santana (PCdoB). Ainda foram reeleitas Benedita da Silva (PT) como deputada federal pelo Rio de Janeiro e Leci Brandão (PCdoB) como deputada estadual em São Paulo.

O sentimento de indignação diante da execução e também da lentidão para descobrir os mandantes do crime político, motivaram inúmeros atos novamente pelo país e ao redor do mundo, sendo enfatizada sobre a relevância do legado de Marielle Franco também durante os atos do 8 de março. Segundo o site Florescer por Marielle (2019), em janeiro de 2019 "o jornal inglês The Guardian lançou documentário sobre Marielle, mostrando mais uma vez a dimensão internacional da luta por justiça”.

Marielle Franco foi morta por representar a ousadia de ocupar o espaço considerado inadequado para mulheres negras LGBTQ+ faveladas e socialista. Ela foi morta porque rompeu várias barreiras para chegar naquele espaço e não se curvou aos interesses dominantes. A repercussão em um município do interior da Bahia, com uma forte presença de desigualdades sociais, raciais e sexuais, como dito na introdução, ganhou inicialmente contornos de indignação e mobilização de um pequeno grupo de pessoas para o espaço público e posteriormente, um ano depois, repercutiu positivamente sobretudo dentro da Universidade, a partir da identificação das/os estudantes com as causas defendidas por Marielle Franco.

Em vista dos acontecimentos de todos os atos, podemos observar a crescente produção literária de obras com foco no enfrentamento das desigualdades sociais, de gênero e de raça. O número de músicas produzidas tendo um viés de denúncia aumentou de forma muito rápida; o rap tem sido a voz predominante quando traz a memória de Marielle como símbolo de resistência e justiça social. Vale destacar também o samba-enredo da escola de samba Mangueira, que neste ano (2019) levou para o sambódromo do Rio de Janeiro o canto de resistência para o carnaval.

Na poesia, tivemos várias produções também em sua memória, com narrativas que clamam por justiça, equidade e efetivação dos direitos. Os movimentos estudantis nas universidades passaram a dialogar sobre as causas de violências, a morosidade do sistema, o 
protagonismo do estudante, houve maior mobilização dentro das instituições de ensino.

Todavia, mesmo que tenha sido um impulso inicial para a organização coletiva, em Barreiras não se manteve e a dispersão voltou a ocupar o espaço principal, inclusive pela conjuntura política de ascensão de ideias de extrema-direita com a eleição de Jair Bolsonaro e do indício de envolvimento da família Bolsonaro com o crime (ainda sob investigação) e de organização de adeptos do bolsonarismo em Barreiras.

No entanto, a referência de Marielle inspirou individualmente muitas pessoas, em especial jovens mulheres e homens negros, permanecendo o desafio de retomar o legado de Marielle no que tange à coletividade. É importante salientar que os principais autores artísticos e os/as protagonistas dos movimentos sociais, são pessoas com realidade parecida com a de Marielle Franco, geralmente são pessoas vindas das periferias, marginalizadas pela sociedade e pelo sistema político.

\section{Referências}

ANTUNES, Leda. As sementes de Marielle Franco: Quem são as mulheres negras eleitas em 2018. HuffPost Brasil, 10 de outubro de 2018. Disponível em: <https://www.huffpostbrasil.com/2018/10/10/assementes-de-marielle-franco-quem-sao-as-mulheres-negras-eleitasem-2018_a_23557207/> Acesso em: 29 dez. 2019.

CAZARRÉ, Marieta. Imprensa internacional repercute morte da vereadora Marielle Franco. Agência Brasil, Lisboa, 15 de março de 2018. Disponível em: <http://agenciabrasil.ebc.com.br/geral/noticia/ 2018-03/imprensa-europeia-repercute-morte-de-marielle-franco > Acesso em: 30 dez. 2019.

FLORESCER por Marielle, 2019. Disponível em: https:// www.florescerpormarielle.com.br/quem-foi-marielle/. Acesso em: 28 dez. 2019.

FRANCO, Marielle. A redução da favela a três letras: uma análise da política de segurança pública do estado do Rio de Janeiro. 2014. $136 \mathrm{f}$. Dissertação (Mestrado em Administração) - Faculdade de Administração, Ciências Contábeis e Turismo, Universidade Federal Fluminense. Rio de Janeiro, 2014. 
FUKS, Rebeca. Marielle Franco: Política e socióloga brasileira. ebiografia, 2019. Disponível em: <https://www.ebiografia.com/ marielle_franco/> Acesso em: $30 \mathrm{dez} .2019$.

hooks, bell. Intelectuais negras. Estudos Feministas, Vol. 3, $\mathrm{N}^{0}$ 2, 1995,p. 465-477.

IBGE. População Barreiras. Disponível em: <https:// cidades.ibge.gov.br/brasil/ba/barreiras/panorama> Acesso em: 29 dez. 2019.

MARIELLE Franco conta sua história. Rio de Janeiro: Diário do Centro do Mundo, 2018. Son., color. Disponível em: <https:// www.youtube.com/watch?v=-gUVlxFsnGo>. Acesso em: 30 dez. 2019.

MARIELLE Franco: 1 ano de saudades, uma vida inteira de luta. Marielle Franco, 2019. Disponível em: < https:// www.mariellefranco.com.br/> Acesso em: 28 dez. 2019.

MÍDIA internacional repercute assassinato de Marielle destacando sua luta política. Brasil de Fato, São Paulo (SP), 15 de março de 2018. Disponível em: <https://www.brasildefato.com.br/2018/o3/15/midiainternacional-repercute-assassinato-de-marielle-destacando-sua-lutapolitica/> Acesso em: 30 dez. 2019.

QUEM é Marielle Franco?. Rio de Janeiro: Marielle Franco, 2016. Son., color. Disponível em: <https://www.youtube.com/watch? v=DPs207VgwJA $>$. Acesso em: 30 dez. 2019. 


\section{Marielle Seeds in the Cerrado Baiano}

ABSTRACT: The repercussion of the execution of the councilwoman and activist Marielle Franco was national, international and also local. In this brief experience report, we aim to reflect on the legacy of Marielle Franco for from three public acts held in the municipality of Barreiras, inland of Bahia, in 2018 and 2019. We resumed his biography and the dissemination of the crime; then we report and analyze the two public acts performed by PSOL-Barreiras in Castro Alves Square, in 2018 and 2019 and the public act organized by the Student Movement of the Bahia State University, Campus IX. The informations about Marielle Franco, his trajectory, and crime comes primarily from journalistic sources and videos available on YouTube or on his political memory site. From distinct speech location, we evaluate the reflections of Marielle's legacy to drive artistic creation, the identification with blackness, the organization and strengthening of social movements, black women's candidacies and the difficulties in the political scenario of the rise of the far right, including in Barreiras.

KEYWORDS: Marielle Franco. Legacy. Acts. Barreiras.

Paula VIELMO

Pedagoga do Instituto Federal de Educação, Ciência e Tecnologia da Bahia (IFBA), Campus Barreiras; especialista em Educação em Gênero e Direitos Humanos (NEIM/UFBA) e mestranda em Estudos Interdisciplinares sobre Mulheres, Gênero e Feminismo (UFBA). Integro o Grupo de Estudos sobre Gênero numa perspectiva Feminista (GEGEF/IFBA) e o Grupo de Pesquisa CIGE - Estudos de Gênero em Ciência e Educação (UFBA).

\section{Indiara de Souza CONCEIÇÃO}

Graduanda de Letras na Universidade do Estado da Bahia, Campus IX em Barreiras; participante do Programa de Iniciação a Docência (PIBID/UNEB). Participo do grupo de Estudos sobre gênero numa perspectiva Feminista (GEGEF/

IFBA).

Raycá da Silva MORAIS

Graduando de Letras na Universidade do Estado da Bahia, Campus IX em Barreiras.

Recebido em: 31/12/2020 | Aprovado em: 12/10/2020 